\title{
Apresentação e Análise de Trabalhos Acerca da Distribuição dos Alunos por Sexo nas Aulas de Educação Física Escolar
}

\author{
Mauro Louzada de Jesus * \\ Fabiano Pries Devide ** \\ Sebastião Votre ${ }^{* * *}$
}

\begin{abstract}
Resumo: O objetivo deste ensaio é apresentar e analisar trabalhos contemporâneos que se relacionam com a distribuição dos alunos por sexo nas aulas de Educação Física e se caracteriza como pesquisa qualitativa de caráter descritivo. Como referencial teórico-metodológico, utilizou-se a Análise do Conteúdo. Foram utilizados dez trabalhos acadêmicos no período de 1990 até 2004. A análise indica que os autores são a favor das turmas mistas, com exceção de um. Defende-se neste estudo a não polarização das turmas, com vistas a um melhor aproveitamento dos potenciais do trabalho com turmas mistas e separadas por sexo.
\end{abstract}

Palavras-chave: Educação física. Ensino. Identidade de gênero. Literatura de revisão.

\section{INTRODUÇÃO}

A temática deste ensaio torna-se central nos tempos atuais em que a Educação Física representada pelos esportes, ginástica, jogos, lutas, dança, coexistem na escola. Se antes a Educação Física possuía objetivos como a aptidão física e a performance, nos dias de hoje possui uma diversidade de conteúdos e objetivos. Se antes recomendava-se para as atividades físicas a separação dos alunos

"Mestre em Educação Física. Prof da Unisuam-RJ, da Rede Estadual Ensino do Rio de Janeiro e da Rede Municipal de Ensino-Teresópolis-RJ, Brasil. E-mail: mauro.tere @uol.com.br

" Doutor em Educação Física e Cultura. Profo de Pós-graduação em Ciências da Atividade Física (PGCAF/Universo) e Profo. da Unisuam-RJ, Brasil.

E-mail: fabianopriesdevide@ mailbr.com.br

Doutor e livre-docente em lingüística. Profo titular da UFRJ (aposentado). Profo titular da UGFRJ e associado na UFF, Brasil. E-mail: sebastianovotre@yahoo.com 
por sexo, atualmente, há uma grande polêmica sobre o que é mais indicado: separar ou unir os alunos por sexo nas aulas de Educação Física.

O objetivo deste ensaio é apresentar e analisar alguns trabalhos contemporâneos que se relacionam com a distribuição dos alunos por sexo nas aulas de Educação Física. Procuramos abordar algumas teses e dissertações apresentando pontos centrais relacionados com o tema.

Como delimitação da pesquisa consultamos dois bancos de dados: Núcleo Brasileiro de Dissertações e Teses em Educação Física e Educação Especial (NUTESES) e o catálogo da Biblioteca da Universidade Gama Filho. Procuramos por trabalhos desenvolvidos no período de 1990 até 2004. Encontramos dez trabalhos acadêmicos - sete dissertações de mestrado e três teses de doutorado - que se relacionam direta ou indiretamente com o tema distribuição dos alunos por sexo nas aulas de Educação Física escolar.

O trabalho caracteriza-se como uma pesquisa qualitativa de caráter descritivo baseado em uma análise documental das dissertações e teses que versavam sobre a temática em foco. Como referencial teórico-metodológico nos servimos da Análise do Conteúdo (BARDIN, 1977). A consulta foi realizada com as seguintes intenções: i)conhecer as propostas dos pesquisadores; ii)avaliar o grau de viabilidade de cada proposta, levando em consideração o suporte teórico e pedagógico da mesma; iii)dependendo do resultado dos dois primeiros itens, avançar com uma proposta de intervenção, em que novos ingredientes se acresçam.

A questão ou problema central da pesquisa foi: o que os trabalhos pesquisados apresentam acerca da distribuição dos alunos por sexo nas aulas de educação física?

\section{Apresentação e ANÁlise dos trabalhos}

Os trabalhos analisados estão descritos a seguir em ordem cronológica de publicação:

Mavimento, Porto Alegre, v. 14, n. 02, p. 83-98, maio/agosto de 2008. 
Neíse Gaudencio Abreu (ABREU, 1990, p. 7), em sua dissertação de mestrado, supõe uma escola modelo: "Imagino uma escola-modelo onde os alunos são críticos, participantes, conscientes de seu papel como cidadãos". Constatando que os alunos preferem as turmas separadas por sexo para as aulas de Educação Física, justifica essa preferência a partir de determinantes sociais. Para ela, na prática tecnicista, é normal que se separe, mas na prática humanista, não. Não procura convencer-nos a fazer aulas com turma mista, mas discute os problemas que surgem entre meninos e meninas durante essas aulas. Sugere outros critérios, além do gênero, para distribuição dos alunos nas aulas de Educação Física, tais como: níveis de experiência motora, números pares e ímpares da chamada e oferecimento de modalidades. Considera que a separação das turmas por sexo não faz sentido, na medida em que é baseada em estereótipos culturais. Não vê vantagens nas turmas separadas por esse critério e afirma que a integração entre meninos e meninas justifica as turmas mistas. Sua posição é contrária à maioria dos docentes e discentes que consultou, pois o consenso de seus informantes é que as aulas sejam em turmas separadas por sexo. A autora defende a idéia de que as meninas podem, com as mesmas oportunidades, chegar ao patamar dos meninos. Isso nos parece difícil, quase impossível, pois, devido a fatores de ordem biológica, as meninas possuem níveis inferiores de força, agilidade e resistência, se comparadas a meninos da mesma idade.

Elaine Romero (ROMERO, 1990), em sua tese de doutorado sobre estereótipos masculinos e femininos em docentes, constatou que a escola é reprodutora de uma ideologia sexista. Segundo ela, fora da escola os meninos são mais estimulados a desenvolver a coordenação ampla, o que os favorece nas aulas de Educação Física escolar, enquanto as meninas são educadas num padrão de comportamento que reforça a submissão, a dependência e a repressão ao corpo, o que as impede de desenvolver de modo adequado a motricidade, gerando dificuldade maior nas aulas. O professor de Educação Física deveria preocupar-se em amenizar as questões conflituosas acerca de comportamentos sexuais culturalmente estereotipados. Nas aulas, pelo fato de os meninos serem mais desenvolvidos nos aspectos físico-motor, eles passam a ter mais oportunidades e a receber mais 
atenção dos professores. Por isso, aulas com conteúdos esportivos tendem a favorecer os meninos. Quando a aula é jogo, geralmente os meninos vão para o futebol, e as meninas, para o queimado. A autora afirma que as atividades físicas não deveriam estar condicionadas ao sexo, o que nos permite inferir que é a favor dos mesmos conteúdos para meninos e meninas. A autora sugere que os paisprofessores e as mães-professoras se empenhem em oferecer igualdade de oportunidades para seus filhos e filhas. Sugere também que, na escola, não seja o sexo o fator determinante da prática curricular, e que a escola reveja suas práticas no sentido de tratar igualmente meninos e meninas. Constata, no universo pesquisado que, desde a pré-escola, as crianças são separadas por sexo para Educação Física.

Segundo nossa interpretação, fazer com que meninos e meninas executem as mesmas atividades significa, muitas vezes, ir contra suas identidades de gênero. Cabe uma reflexão sobre o que devemos propor aos meninos e meninas como conteúdos.

Maria do Carmo Saraiva-Kunz (SARAIVA-KUNZ, 1993), em sua dissertação de mestrado, constata discriminações entre meninos e meninas na Educação Física e no esporte. Seu interesse pela pesquisa se deu pela dificuldade em ministrar aulas para turmas mistas. A partir de sua experiência profissional, afirma que rupturas nos relacionamentos entre meninos e meninas na Educação Física e no esporte são causadas pelo estereótipo sexual. O condicionamento aos estereótipos levou à discriminação dos papéis sociais de homens e mulheres e relegou a mulher a papéis subordinados ao homem.

Em relação ao esporte como conteúdo central da Educação Física escolar, a autora diz que este reforça as polaridades patriarcais do sexo e gera uma socialização com sexos em separado.

Na Educação Física escolar, reconhece duas correntes teóricas: i)corrente progressista, que defende aulas com turmas mistas e aposta na educação como meio para melhorar as relações sociais; ii)corrente tradicionalista que defende aulas com turmas separadas por sexo e postula uma Educação Física escolar com fins de rendimento e aptidão física. A autora apresenta uma proposta de intervenção pedagógica baseada no conceito de co-educação, segundo o qual, além das 
discussões sobre as questões de gênero, os meninos adquirem a cultura das meninas e vice-versa. Segundo Saraiva-Kunz (1993) meninos e meninas somente terão oportunidades iguais em aulas co-educativas.

A autora constatou que as meninas reclamam dos meninos por eles serem "agressivos" em suas atitudes com os erros delas. Os meninos também reclamam delas, dizendo que são muito "frescas" e não entendem o que elas querem na aula. As situações de conflitos e discriminação entre meninos e meninas, segundo a autora, podem ser sanadas com estratégias que privilegiem a cooperação e a solidariedade.

Saraiva-Kunz (1993) defende os direitos da mulher e propõe uma Educação Física transformadora. O esporte, principal conteúdo da Educação Física escolar, pode ser praticado em turmas mistas, mas também em turmas separadas por sexo, nas quais a Educação Física escolar terá outros objetivos - afinal, as diferenças de força, agilidade e resistência pesam muito a favor dos meninos.

Segundo nossa interpretação, a proposta da autora deve ser considerada e aproveitada, mas adaptada às circunstâncias e aos interesses de meninos e meninas. Devemos também privilegiar situações em que meninos e meninas se sintam mais à vontade para se desenvolverem.

Eustáquia Salvadora de Sousa (SOUSA, 1994), em sua tese de doutorado, questiona a separação dos alunos por sexo, pois é francamente a favor das turmas mistas. Analisa a organização dos alunos por sexo em todos os níveis de ensino, de 1887 até 1994, descrevendo em cada momento da história como eram organizadas as turmas e por quais razões ocorriam as turmas mistas ou separadas. Afirma que, em sua infância, gostava de brincar de boneca e futebol, mas a segunda atividade era um problema para seus pais, que não a viam com bons olhos.

A autora confirma uma tendência à dicotomização da distribuição dos alunos por sexo e menciona uma disciplina do currículo do curso de graduação que oportuniza aulas mistas: "É importante lembrar que, desde 70, a recreação vem dando oportunidade de 
vivência de atividades, praticadas, em conjunto [...] e, nos anos 90, introduziu, sistematicamente, as relações de gênero como questão de estudo" (SOUSA, 1994, p. 159). Relata que, em 1987, as escolas estaduais funcionavam com turmas mistas de Educação Física, e que, em 1990, os professores de escolas municipais de Belo Horizonte se mobilizaram contra a implantação de turmas mistas. A adoção dessas turmas nos colégios estaduais e municipais gerou uma revolta dos docentes que, fundamentados em aspectos legais, nas diferenças biológicas e/ou psicológicas entre meninos e meninas, e na necessidade de se manter a qualidade de ensino, se uniram para revogar a norma. Todavia, a mesma foi mantida.

Uma grande preocupação da autora é com a denúncia das questões de gênero que seriam facilitadas em turmas mistas. Ela propõe uma educação mista e sem discriminações, oportunizando a todos os alunos vivências lúdicas.

Vemos a proposta da autora como positiva; todavia, entendemos que a turma mista é apenas uma forma de distribuição dos alunos, e que trazem alguns benefícios. Entendemos que existem outras formas de distribuição que podem ser exploradas no sentido de buscar experiências variadas.

Greice Kelly de Oliveira (OLIVEIRA, 1996), em sua dissertação de mestrado, verificou que se, por um lado, a separação dos alunos por sexo favorece um maior rendimento esportivo, por outro, com turmas mistas favorece o amadurecimento e a integração.

A autora discute as diferenças sexuais e as adquiridas. Para ela, muitas diferenças consideradas naturais são construídas socialmente e, essas diferenças, muitas vezes privam meninos e meninas da convivência nas aulas de Educação Física. Para ela, em turmas mistas reside um potencial para melhor preparar o indivíduo para a vida extra-escolar, desde que o professor dê a mesma atenção aos meninos e às meninas e que os considere com suas particularidades, tratando cada um de acordo com a sua individualidade.

Baseada nos dados, a autora constata que, em vez de criar novos valores, a escola reproduz as relações de gênero. $O$ futebol tem sido um dos principais motivadores da dificuldade de integração 
entre meninos e meninas nas aulas de Educação Física. A autora não considerou a possibilidade de aulas alternando as formas de distribuição. Privilegia os objetivos sociais na Educação Física escolar e defende que estes devem ser trabalhados melhor em aulas mistas.

É nossa opinião, contudo, que também em aulas separadas podemos trabalhar objetivos sociais.

José Luiz Ferreira (FERREIRA, 1996), em sua dissertação de mestrado observou aulas da escola primária e constatou que eram constituídas de três partes, em que o professor: $1^{\circ}$ )conversava com a turma sobre a aula; $2^{\circ}$ )orientava uma atividade mista; $3^{\circ}$ )dividia meninos e meninas para jogarem futebol e baleada, respectivamente.

$\mathrm{Na}$ análise dos dados, Ferreira (1996) identificou duas categorias: "contradição" na prática do professor e "participação" dos alunos. Existia uma contradição entre o discurso e a prática do professor, contribuindo para o quadro de discriminação entre meninos e meninas. Segundo Ferreira (1996, p. 68), o professor dizia que era importante a prática conjunta de meninos e meninas, mas “[...] negava ao final de cada aula a co-participação, separando a turma por sexo e fazendo para cada um dos grupos o tipo de atividade supostamente entendida como feminina ou masculina". Sobre a segunda categoria, a "participação" nas aulas de Educação Física é maior para o sexo masculino: enquanto os meninos algumas vezes participavam da baleada, as meninas nunca participavam do futebol. O professor, durante as aulas, prestava mais atenção ao futebol dos meninos do que à baleada das meninas.

$\mathrm{O}$ autor defende que meninos e meninas tenham as mesmas oportunidades de participação nas aulas. Essa participação, segundo ele, só poderá ser alcançada a partir da compreensão das contradições da sociedade capitalista em busca de uma sociedade igualitária do ponto de vista de gênero. Ele acrescenta que a Educação Física é sexista, pois trabalha com turmas separadas para determinadas atividades e privilegia um sexo em detrimento do outro.

A partir de uma visão macro da sociedade, baseada no materialismo histórico-dialético, Ferreira interpreta as relações de gênero 
nas aulas de Educação Física como um espelho das relações capitalistas, em que uma minoria detentora de poder explora a maioria. Propõe que o professor tenha em sua prática pedagógica uma postura transformadora, buscando discutir, entre outras coisas, as questões de gênero.

A partir de uma visão centrada nas questões de gênero, Ferreira (1996) considera apenas o caminho das turmas mistas como detentor de possibilidades de mudanças. Vemos, porém, que em sua observação encontrou uma prática em que o professor alternava momentos com turmas separadas por sexo e momentos com turma mista. Será que somente em turmas mistas existem vantagens? O trabalho com turmas separadas por sexo não traz nenhum benefício para os alunos?

Helena Altmann (ALTMANN, 1998) pesquisou em sua dissertação de mestrado uma escola com turmas mistas, constatando que os meninos iam para o futebol, e as meninas, para o voleibol. Quando meninas jogavam futebol, alguns meninos na arquibancada chamavam-nas de "Maria-homem". Dentre os problemas vividos nas turmas mistas, cita: i)meninas reclamavam de meninos por estes não passarem a bola; ii)meninos reclamavam das meninas por estas errarem no jogo; iii)meninas reclamavam que os meninos no voleibol ficavam chutando a bola; iv)meninas reclamavam da violência dos meninos. No jogo de voleibol, os meninos tocavam na bola três vezes mais do que as meninas. A autora verificou que a professora alterava as regras para aumentar a participação feminina no jogo. Essa alteração quebrava a dinâmica do jogo, e a responsabilidade era imputada às meninas, pois a professora havia mudado as regras por causa delas.

Segundo Altmann (1998, p. 96), na escola, “[...] os jogos simultaneamente demarcavam e propiciavam meios de cruzar as fronteiras da masculinidade e da feminilidade, possibilitando, ainda, relações variadas entre meninos e meninas". Ao cruzarem as fronteiras, as meninas ofereciam resistência à dominação masculina. Altmann (1998) admite que o ensino de Educação Física para turmas mistas apresenta vantagens e desvantagens. Os alunos ora respondiam que eram melhores as turmas separadas por sexo, ora que eram 
melhores as turmas mistas. Os seus gostos variavam segundo: i)a atividade; ii)quem estivesse jogando; iii)o momento em que ocorresse a atividade (aula, recreio, competições esportivas); iv)o número de participantes (com muitos participantes ocorriam mais conflitos). Ela conclui que as formas de organização dos alunos por sexo na Educação Física podem variar de acordo com as circunstâncias e atividades realizadas. Admite ainda a possibilidade de variar as formas de distribuição dos alunos por sexo. Afirma serem bem aceitas tanto as turmas mistas quanto as separadas por sexo.

Eliete do Carmo Garcia Verbena (VERBENA, 2001), em sua dissertação de mestrado, constatou que as aulas de Educação Física nas $7^{\mathrm{a}}$ e $8^{\mathrm{a}}$ séries eram ministradas fora do horário normal das outras disciplinas, com turmas separadas por sexo.

Para a autora, existe uma distinção entre o que se espera de meninos e de meninas. Delas espera-se coordenação motora fina, reforçando as características de harmonia e delicadeza. Deles, o incentivo à prática de atividades físicas que desenvolvam a coordenação ampla, num ambiente em que não é permitido chorar, numa forma de treinamento para a vida do trabalho.

Segundo Verbena (2001) é necessária a atuação docente no sentido de: i)romper com a ideologia sexista que reina na sociedade; ii)desenvolver o respeito entre meninos e meninas; iii)combater a discriminação e os preconceitos, principalmente em relação às meninas. A autora constatou o domínio dos espaços esportivos pelos meninos e as agressões verbais dos meninos contra as meninas, dificultando o trabalho misto, devido a uma ideologia machista que impera no mundo esportivo masculinizado. Mostra o quanto é difícil implementar ações com turmas mistas nas aulas de Educação Física, principalmente quando o conteúdo é o esporte.

$\mathrm{Na}$ entrevista que realizou com os discentes, perguntou o que eles pensavam das aulas com turmas mistas. As meninas, na sua maioria, foram contra, e os meninos, na sua maioria, foram a favor. Os que foram a favor das aulas com turmas mistas apresentaram os seguintes argumentos: i)troca/ ajuda; ii)prazer; iii)respeito; 
iv)conteúdos variados. Já os que foram contra as aulas com turmas mistas, na sua maioria meninas, apresentaram as seguintes justificativas: i)interesses diferenciados; ii)agressividade; iii)habilidade masculina/inabilidade feminina; iv)falta de privacidade; v)adequação esportiva.

Cátia Pereira Duarte (DUARTE, 2003, p. 83), em sua dissertação de mestrado, investiga: "[...] por que ainda se admite separação de atividades de acordo com os sexos nas aulas?".

Em aulas que deveriam ser com turmas mistas, flagrou as turmas separadas por sexo para as atividades; “[...] todos os professores, embora concebendo suas aulas como mistas, preferem separar os meninos das meninas" (DUARTE, 2003, p. 94). Eles justificam dizendo que as diferenças interferem na aprendizagem. Apesar da Secretaria Municipal de Educação determinar aulas com turmas mistas, o quadro de separação prevalecia. De quatro docentes, três separavam os alunos nas aulas. Um dos motivos era não expor as poucas habilidades das meninas à gozação dos meninos. Outro motivo alegado era que os meninos são brutos e as meninas são mimadas. Quando o educador solicitava que os educandos realizassem atividades em grupo, meninos se aproximavam de meninos, e meninas de meninas.

A autora defende de forma convincente as turmas mistas. Contudo, a nosso ver, são várias as razões para se justificar ambas as formas de distribuição dos alunos.

Sissi Aparecida Martins Pereira (PEREIRA, 2004), em sua tese de doutorado, encontrou preferência para as turmas separadas por sexo para as atividades lúdicas, embora a escola oriente as docentes para que as aulas se dêem com turmas mistas. Na coleta dos dados, a maioria dos desenhos dos alunos mostra a separação de meninos e meninas para as atividades. A autora constatou que ambos ocupavam espaços diferentes nas atividades lúdicas na hora da recreação. Poucos meninos brincavam junto com as meninas no pátio, e estas brincavam menos ainda com os meninos no campo de futebol.

Movimento, Porto Alegre, v. 14, n. 02, p. 83-98, maio/agosto de 2008. 
A autora se posiciona a favor das turmas mistas e critica a separação:

\begin{abstract}
A escola tem papel social fundamental e causa preocupação a separação por sexo nas aulas de Educação Física. Se os alunos estão freqüentemente solicitando esta separação, a conduta acrítica do professor acaba permitindo que as diferenças continuem se arrastando. (PEREIRA, 2004, p. 29)
\end{abstract}

Entendemos que o professor pode atender aos anseios dos alunos. Um fato importante é a preferência da maioria dos alunos por turmas separadas por sexo nas aulas de Educação Física escolar. Como a motivação é um fator importante no processo ensino-aprendizagem, os professores podem aproveitar a tendência de meninos e meninas de fazerem atividades separadas por sexo para desenvolverem suas aulas, ora mistas, ora separadas.

A habilidade ocupa lugar importante no estudo: "Os meninos não querem jogar com as meninas nem com os menos habilidosos" (PEREIRA, 2004, p. 29). Para ela, a separação entre meninos e meninas se origina na sociedade e é perpetuada pela escola. Os meninos e meninas possuem gostos diferentes entre si, o que fica comprovado em suas condutas. Se trabalharmos só com atividades mistas não estaremos restringindo os potenciais masculinos e femininos que se expressam com mais intensidade nas aulas de Educação Física escolar? Com certeza, alguns objetivos são muito melhor desenvolvidos em turmas separadas. A nossa proposta é que se utilizem turmas mistas e separadas para explorar todas as possibilidades destas turmas.

Finalizando a análise documental, os quadros 1 e 2 apresentam o posicionamento dos autores face à distribuição dos alunos por sexo nas aulas de Educação Física e as fontes de informação por eles utilizadas. 


\begin{tabular}{|c|c|c|c|c|c|c|c|c|c|c|}
\hline Posicionamento & 吾 & 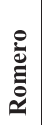 & 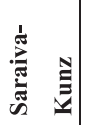 & 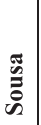 & $\frac{\pi}{0}$ & 矛 & 莺 & 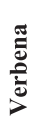 & 芫 & $\frac{5}{2}$ \\
\hline Defende somente turmas mistas & & & $\mathrm{X}$ & $\mathrm{X}$ & $\mathrm{X}$ & $\mathrm{X}$ & & $\mathrm{x}$ & $\mathrm{X}$ & $\mathrm{X}$ \\
\hline $\begin{array}{l}\text { Defende turmas mistas e separadas, } \\
\text { dependendo das circunstâncias }\end{array}$ & & & & & & & $X$ & & & \\
\hline $\begin{array}{l}\text { Defende turmas mistas e outras formas } \\
\text { de divisão dos alunos, com exceção das } \\
\text { turmas separadas por sexo }\end{array}$ & X & & & & & & & & & \\
\hline $\begin{array}{l}\text { Não se posiciona explicitamente, mas } \\
\text { permite que se infira a sua preferência } \\
\text { por turmas mistas }\end{array}$ & & $\mathrm{x}$ & & & & & & & & \\
\hline
\end{tabular}

Quadro 1 - Posicionamento dos autores face à distribuição dos alunos nas aulas de Educação Física

\begin{tabular}{|c|c|c|c|c|c|c|c|c|c|c|}
\hline Fontes & $\begin{array}{l}\overline{0} \\
\frac{0}{2}\end{array}$ & $\begin{array}{l}\stackrel{0}{\mathscr{\Xi}} \\
\stackrel{0}{0}\end{array}$ & 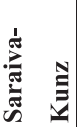 & 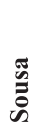 & $\frac{\pi}{0}$ & 丞 & 胥 & 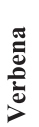 & 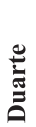 & : \\
\hline Professores & & $\mathrm{X}$ & & & & & & & & \\
\hline Professores e alunos & $\mathrm{X}$ & & & & & $\mathrm{X}$ & $\mathrm{X}$ & & & $\mathrm{X}$ \\
\hline Alunos & & & $\mathrm{X}$ & & $\mathrm{X}$ & & & $\mathrm{X}$ & $\mathrm{X}$ & \\
\hline $\begin{array}{l}\text { Documentos, história de vida de seis } \\
\text { professores, depoimentos de } \\
\text { professores, alunos, coordenadores, } \\
\text { técnicos administrativos, e iconografia }\end{array}$ & & & & $\mathrm{X}$ & & & & & & \\
\hline
\end{tabular}

Quadro 2 - Fontes de informação utilizadas pelos autores

\section{Considerações finaIS}

Os trabalhos analisados trazem, para a Educação Física escolar, as questões de gênero que emergem nas aulas, como os estereótipos de gênero e sexo, os conteúdos discriminados para meninos e meninas, e a discriminação de gênero. Os autores defendem explicitamente as turmas mistas, com exceção de Helena Altmann (1998), que considera a possibilidade de variação nas formas de organização dos

Mavimento, Porto Alegre, v. 14, n. 02, p. 83-98, maio/agosto de 2008. 
alunos por sexo. Alertam para um novo contexto na Educação Física escolar, em que as aulas com turmas separadas por sexo são contestadas e as mistas são defendidas. Chamamos a atenção para o fato de, embora a quase totalidade dos trabalhos aqui analisados defenda o trabalho em turmas mistas, Durand-Delvigne e Duru-Bellat (2003) reportaram resultados contrários: em seu estudo, as meninas tendem a subestimar suas potencialidades, inibidas pela presença dos meninos. Infere-se, pois, que o trabalho misto em alguns momentos pode ser mais indicado, enquanto em outros as turmas separadas são mais indicadas.

Defende-se neste estudo uma não polarização das turmas, com vistas a um melhor aproveitamento dos potenciais do trabalho com turmas mistas e separadas por sexo.

Em vários estudos manifesta-se resistência por parte dos professores e alunos para a organização das turmas mistas. Mesmo depois de vários anos em que turmas mistas vêm sendo oferecidas aos professores pelas escolas, Louzada e Devide (2004), em pesquisa com alunos do Ensino Médio, encontraram respostas dos alunos a favor das turmas separadas por sexo. As meninas justificaram a turma separada devido ao fato de os meninos serem brutos e discriminarem-nas, enquanto para os meninos a justificativa é que em turmas separadas a intensidade da aula é maior.

Não nos posicionamos de forma polarizada face às formas de organização das turmas por sexo. Propomos não ser a radicalização o melhor caminho, visto que ambas as formas de organização trazem vantagens aos alunos. A Educação Física escolar deve ir em busca de uma educação plural, e, para isto, deve explorar todos os instrumentos, estratégias e metodologias que colaborem para este fim. 
Presentation and Assignment Analysis on Gender Student Division in Physical Education Classes Abstract: The aim of this essay is to present and analyze contemporary assignments related to student division concerning gender during the Physical Education classes. This study is based on a qualitative research within a descriptive approach. A Content Analysis has been used as a theoretical-methodological framework. Ten different academic studies written between 1990 and 2004 were found. The analysis has shown that nine out of ten writers are in favor of having classes with mixed gender students. This study defends the nonpolarization of the classes in order to reach better outcomes when it comes to work either with mixed-gender groups or separated-gender groups.

Keywords: Physical Education. Teaching. Gender identity. Review literature.

Presentación Y Análisis De Trabajos A Cerca De La Distribución De Los Alumnos Por Sexo En Las Clases De Educación Física

Resumen: El objetivo de este ensayo es presentar y analizar trabajos contemporáneos que son relativos a la distribución de los alumnos por sexo en las clases de educación física. Este estudio se caracteriza como una pesquisa cualitativa de carácter descriptivo. Como referencial teórico-metodológico, se utilizó el Análisis del Contenido. Fueran encontrados diez trabajos académicos en el período de 1990 hasta 2004. El análisis indicado que los autores son a favor de los grupos mixtos, con excepción de uno. Se defiende en este estudio la no-polarización de los grupos, con vistas a una mejor utilización de los potenciales del trabajo con grupos mixtos y separados por sexo.

Palabras-clave: Educación física. Enseñanza. Identidad de género. Literatura de revisión.

\section{REFERÊNCIAS}

ABREU, N. G. Meninos pra cá, meninas pra lá. 1990. 162 f. Dissertação (Mestrado em Educação Física) - Programa de Pós-graduação em Educação Física, Universidade Gama Filho, Rio de Janeiro, 1990.

ALTMANN, H. Rompendo fronteiras de gênero: Marias (v) homens na Educação Física. 1998. 111 f. Dissertação (Mestrado em Educação) - Programa de Pós-graduação em Educação, Universidade Federal de Minas Gerais, Belo Horizonte, 1998.

Mavimento, Porto Alegre, v. 14, n. 02, p. 83-98, maio/agosto de 2008. 
BARDIN, L. Análise de conteúdo. Lisboa: Edições 70, 1977.

DUARTE, C. P. $O$ discurso de escolares adolescentes femininas sobre os critérios de seleção utilizados para a participação em aulas mistas de Educação Física. 2003. 121 f. Dissertação (Mestrado em Educação Física) - Programa de Pós-graduação em Educação Física, Universidade Gama Filho, Rio de Janeiro, 2003.

DURAND-DELVIGNE, A.; DURU-BELLAT, M. Co-educação e construção do gênero. In: MARUANI, M.; HIRATA, H. (Org.). Homens e mulheres no mercado de trabalho. São Paulo: Senac, 2003. p. 101-110.

FERREIRA, J. L. As relações de gênero nas aulas de Educação Física: um estudo de caso em uma escola pública de Campina Grande. 1996. 180 f. Dissertação (Mestrado em Educação) - Programa de Pós-graduação em Educação, Universidade Federal da Paraíba, João Pessoa, 1996.

LOUZADA, M.; DEVIDE, F. Representações sociais de discentes sobre aulas de Educação Física escolar mistas e separadas por sexo. In: ENCONTRO FLUMINENSE DE EDUCAÇÃO FíSICA ESCOLAR, 8, 2004, Niterói. Anais... Niterói, 2004. v.1, p.322-327.

NUTESES. Núcleo Brasileiro de Dissertações e Teses em Educação, Educação Física e Educação Especial. Universidade Federal de Uberlândia, [1994]. Disponível em:< http://www.nuteses.ufu.br/>.

OLIVEIRA, G. K. Aulas de Educação Física para turmas mistas ou separadas por sexo? Uma análise comparativa de aspectos motores e sociais. 1996. $148 \mathrm{f}$. Dissertação (Mestrado em Educação Física) - Programa de Pós-graduação em Educação Física, Universidade Estadual de Campinas, Campinas, 1996.

PEREIRA, S. A. O sexismo nas aulas de Educação Física: uma análise dos desenhos infantis e dos estereótipos de gênero nos jogos e brincadeiras. 2004. 257 f. Tese (Doutorado em Educação Física) - Programa de Pós-graduação em Educação Física, Universidade Gama Filho, Rio de Janeiro, 2004.

ROMERO, E. Estereótipos masculinos e femininos em professores de Educação Física. 1990. 407 f. Tese (Doutorado em Psicologia) - Programa de Pós-graduação em Psicologia, Universidade de São Paulo, São Paulo, 1990.

SARAIVA-KUNZ, M. C. Quando a diferença é mito: uma análise da socialização específica para os sexos sob o ponto de vista do esporte e da Educação Física. 1993. 167 f. Dissertação (Mestrado em Educação) - Programa de Pós-graduação em Educação, Universidade Federal Santa Catarina, Florianópolis, 1993.

SOUSA, E. S. Meninos à marcha! Meninas, à sombra! A história do ensino da Educação Física em Belo Horizonte (1987-1994). 1994. 265 f. Tese (Doutorado em Educação) - Programa de Pós-graduação em Educação, Universidade Estadual de Campinas, Campinas, 1994.

Movimento, Porto Alegre, v. 14, n. 02, p. 83-98, maio/agosto de 2008. 


\section{Artifos Origimais Mauro Louzada de Jesus, Fabiano Pries...}

VERBENA, E. C. G. Esporte e gênero: representações entre estudantes da rede pública municipal de Juiz de Fora. 2001. 217 f. Dissertação (Mestrado em Educação Física) - Programa de Pós-graduação em Educação Física, Universidade Castelo Branco, Rio de Janeiro, 2001.

Recebido em: 08/05/2007

Aprovado em: 11/02/2008

Movimento, Porto Alegre, v. 14, n. 02, p. 83-98, maio/agosto de 2008. 